Article

\title{
Tumor BRCA Testing in High Grade Serous Carcinoma: Mutation Rates and Optimal Tissue Requirements
}

\author{
Gulisa Turashvili ${ }^{1, *,+} \mathbb{D}$, Conxi Lazaro ${ }^{1,2,3,4,+}$, Shengjie Ying ${ }^{1}$, George Charames ${ }^{1}$, \\ Andrew Wong ${ }^{1}$, Krista Hamilton ${ }^{1}$, Denise Yee ${ }^{1}$, Evangeline Agro ${ }^{1}{ }^{(D)}$, Martin Chang ${ }^{1}$, \\ Aaron Pollett ${ }^{1}$ and Jordan Lerner-Ellis ${ }^{1}$ \\ 1 Department of Pathology and Laboratory Medicine, Mount Sinai Hospital and University of Toronto, \\ Toronto, ON M5G 1X5, Canada; clazaro@iconcologia.net (C.L.); shengjie.ying@mail.utoronto.ca (S.Y.); \\ George.Charames@sinaihealth.ca (G.C.); Andrew.Wong@sinaihealth.ca (A.W.); \\ Krista.Hamilton@sinaihealth.ca (K.H.); Denise.Yee@sinaihealth.ca (D.Y.); \\ Evangeline.Agro@sinaihealth.ca (E.A.); Martin.Chang@uvmhealth.org (M.C.); \\ Aaron.Pollett@sinaihealth.ca (A.P.); Jordan.Lerner-Ellis@sinaihealth.ca (J.L.-E.) \\ 2 Hereditary Cancer Program, Catalan Institute of Oncology, ONCOBELL-IDIBELL, 08908 Barcelona, Spain \\ 3 Cancer Network Consortium for Biomedical Research (CIBERONC), 08908 Barcelona, Spain \\ 4 Women's College Research Institute, Women's College Hospital, Toronto, ON M5S 1B2, Canada \\ * Correspondence: gulisa.turashvili@sinaihealth.ca; Tel.: +1-416-586-4800 (ext. 5931) \\ + These authors contributed equally to this paper as first authors.
}

Received: 4 September 2020; Accepted: 18 November 2020; Published: 21 November 2020

Simple Summary: Approximately $25 \%$ of women diagnosed with tubo-ovarian high-grade serous carcinoma have germline deleterious mutations in $B R C A 1$ or $B R C A 2$, characteristic of hereditary breast and ovarian cancer syndrome, while somatic mutations have been detected in 3-7\%. We set out to determine the mutation rates and optimal tissue requirements for tumor $B R C A$ testing in 291 tissue samples. Initial testing was successful in $78 \%$ and deemed indeterminate in $13 \%$. Repeat testing was successful in $67 \%$ of retested samples, with an overall success rate of $86 \%$. Clinically significant $B R C A$ variants were identified in $17 \%$ of patients. Successful sequencing was dependent on sample type, tumor cellularity and size $(p \leq 0.001)$ but not on neoadjuvant chemotherapy or age of blocks. In summary, our study shows a $17 \%$ tumor $B R C A$ mutation rate, with an overall success rate of $86 \%$. Biopsy and cytology samples and post-chemotherapy specimens can be used, and optimal tumors measure $\geq 5 \mathrm{~mm}$ in size with at least $20 \%$ cellularity.

Abstract: Background: Approximately 25\% of women diagnosed with tubo-ovarian high-grade serous carcinoma have germline deleterious mutations in BRCA1 or BRCA2, characteristic of hereditary breast and ovarian cancer syndrome, while somatic mutations have been detected in 3-7\%. We set out to determine the BRCA mutation rates and optimal tissue requirements for tumor BRCA testing in patients diagnosed with tubo-ovarian high-grade serous carcinoma. Methods: Sequencing was performed using a multiplexed polymerase chain reaction-based approach on 291 tissue samples, with a minimum sequencing depth of 500X and an allele frequency of $>5 \%$. Results: There were 253 surgical samples $(87 \%), 35$ biopsies $(12 \%)$ and 3 cytology cell blocks $(1 \%)$. The initial failure rate was $9 \%(25 / 291)$, including 9 cases (3\%) with insufficient tumor, and $16(6 \%)$ with non-amplifiable DNA. Sequencing was successful in 78\% (228/291) and deemed indeterminate due to failed exons or variants below the limit of detection in 13\% (38/291). Repeat testing was successful in 67\% (28/42) of retested samples, with an overall success rate of $86 \%$ (251/291). Clinically significant (pathogenic, likely pathogenic) variants were identified in 17\% (48/276) of complete and indeterminate cases. Successful sequencing was dependent on sample type, tumor cellularity and size $(p \leq 0.001)$ but not on neoadjuvant chemotherapy or age of blocks $(p>0.05)$. Conclusions: Our study shows 
a $17 \%$ tumor BRCA mutation rate, with an overall success rate of $86 \%$. Biopsy and cytology samples and post-chemotherapy specimens can be used for tumor BRCA testing, and optimal tumors measure $\geq 5 \mathrm{~mm}$ in size with at least $20 \%$ cellularity.

Keywords: high-grade serous carcinoma; BRCA; tumor sequencing; PARP inhibitors

\section{Introduction}

Ovarian cancer is the 7th most common malignancy in women worldwide [1]. Epithelial tumors account for approximately $90 \%$ of all ovarian cancers and are comprised of five distinct disease groups, with different clinical presentations, pathogenesis, chemosensitivity and prognosis [2]. High-grade serous carcinoma (HGSC) is the most common histological subtype of epithelial ovarian cancer accounting for $70 \%$ of cases and majority of deaths, with a median overall survival of 41 months [1,3]. Up to $25 \%$ of women diagnosed with HGSC have germline deleterious mutations in BRCA1 or BRCA2 characteristic of hereditary breast and ovarian cancer syndrome (HBOC) [4-6], while somatic mutations have been detected in 3-7\% [7-12]. Of all patients with tumor BRCA1/2 variants, 54-74\% are germline and $27-46 \%$ are somatic, i.e., present only in the tumor tissue $[10,12-14]$.

The BRCA1 (chromosome 17q21) and BRCA2 (chromosome 13q12.3) are tumor suppressor genes that encode for proteins essential in DNA double strand break repair by homologous recombination (HR) [15-17]. In women with HBOC, cells with a "second-hit" leading to HR deficiency rely on alternative error-prone mechanisms of DNA repair that leads to an increased risk for the development of a variety of malignancies involving the breast as well as ovary, fallopian tube or peritoneum [18,19]. The presence of $B R C A$ mutation in HGSC has important prognostic and predictive implications. Tumor cells with HR deficiency have been shown to display greater sensitivity to platinum-based chemotherapy regimens in both breast and ovarian cancer patients [20-22]. In addition, HR deficient tumors can also be treated with novel poly adenosine diphosphate ribose polymerase (PARP) inhibitors. PARP enzymes are important in DNA single-strand break repair. PARP inhibitors selectively target HR-deficient cancer cells and lead to cell death through the mechanism of synthetic lethality [23-26]. PARP inhibitors have been demonstrated to extend progression free survival in HGSC patients with the greatest effectiveness in patients with BRCA1/2 mutations [27-31].

The first PARP inhibitor Olaparib was approved by the United States Food and Drug Administration (FDA) in 2016 as a maintenance treatment for BRCA-mutated recurrent HGSC following $\geq 3$ lines of chemotherapy, and extended to treatment following first-line chemotherapy in 2018. Tumor BRCA testing and PARP inhibitor monotherapy for the maintenance treatment of adult patients with BRCA-mutated platinum-sensitive relapsed (PSR) HGSC was first approved by Health Canada in April 2016. Currently, tumor BRCA testing is performed reflexively for newly diagnosed HGSC patients in Ontario in several referral centres. Although formalin-fixed paraffin-embedded (FFPE) samples can be used for molecular studies, there is a wide variety of pre-analytical and analytical variables that can affect the performance of molecular assays, including cold ischemic time, length of fixation, storage conditions, age of paraffin blocks etc. [32-34]. The use of FFPE tumor tissue for BRCA variant analysis using next-generation sequencing (NGS) as well as the feasibility of the implementation for such tests in clinical practice have been investigated previously [7,35]. Tumor testing for $B R C A$ variant screening has been suggested to be more efficient in selecting HGSC patients for genetic counseling as well as for PARP inhibitor therapy [13]. A combination of NGS and copy number variant multiplex ligation-dependent probe amplification has been reported to have a sensitivity of $98 \%$ in the training cohort of 50 patients, and 100\% in the prospective cohort of 66 patients [13]. Another prospective analysis of FFPE samples from 223 patients with epithelial ovarian cancer showed that the tumor BRCA testing using NGS had a success rate of $99.1 \%(221 / 223)$, with a $28.1 \%$ rate of 
pathogenic/likely pathogenic mutations and $87 \%$ concordance rate between germline and tumor $B R C A$ tests [36].

In this study, we present the results of tumor BRCA1/2 testing in a cohort of 291 HGSC patients performed in the clinical setting at a tertiary hospital. We report the rate of tumor $B R C A 1 / 2$ mutations, optimal tissue requirements and challenges encountered such as variable quality of tissue samples and success rates following repeat testing.

\section{Results}

\subsection{Overview of Clinical Data}

FFPE samples from a total of 291 patients diagnosed between 2004 and 2019 were received for tumor $B R C A 1$ and $B R C A 2$ analysis during the study period. The median patient age was 65 years (range 34-89). Most (87\%, 253/291) samples were from surgical excisions, with 12\% (35/291) biopsies and $1 \%$ (3/291) cytology cell blocks from peritoneal fluid. Of tissue samples, most cases $(41.2 \%, 120 / 291)$ were ovarian, 11\% (32/291) were tubal and "adnexal" each, 20\% (58/291) were omental, although other tissues were also represented $(16.8 \%, 49 / 291)$. Most patients $(70.8 \%, 206 / 291)$ were chemotherapy naïve (Table 1).

Table 1. Description of the tissue samples analyzed.

\begin{tabular}{cc}
\hline Tissue Type & No (\%) \\
\hline Ovary & $120(41.2)$ \\
Fallopian tube & $32(11.0)$ \\
Adnexa & $32(11.0)$ \\
Omentum & $58(20.0)$ \\
Other & $49(16.8)$ \\
Post neoadjuvant chemotherapy \\
Yes & $85(29.2)$ \\
No & $206(70.8)$ \\
\hline
\end{tabular}

\subsection{Initial Testing}

Tumor cellularity was analyzed by a single pathologist prior to sequencing. Samples with a cellularity of $<10 \%$, irrespective of tumor size, were not eligible for sequencing under the assumption that a heterozygous variant would not meet the 5\% limit of detection for this test. Of 291 samples, $9(3 \%)$ had insufficient tumor with $<10 \%$ cellularity and thus were not submitted for DNA extraction, $16(5.5 \%)$ had suboptimal DNA quality and/or quantity and thus were not submitted for sequencing. Overall, the initial failure rate was 8.6\% (25/291) (Figure 1). Of 266 (91.4\%) samples that were sequenced, complete reports were generated in most cases $(78.4 \%, 228 / 291)$, while $13 \%$ (38/291) was considered indeterminate. Indeterminate reports included those with either failed exons due to the possibility of uncaptured pathogenic or likely pathogenic variants within the failed exons or with pathogenic or likely pathogenic variants below the limit of detection (LOD) due to uncertainty over true presence of clinically significant variants below LOD.

\subsection{Repeat Testing}

Repeat testing was performed in 42 cases, including all 16 failed (insufficient and/or non-amplifiable DNA) samples and 26 of 38 indeterminate (19 with low coverage depth, 11 with variants below the LOD, 1 with a large number of variants of uncertain significance (VUS)) samples (Figure 2). Successful results were obtained in $66.7 \%(28 / 42)$ of cases, $7.1 \%$ (3/42) failed, while the remaining $26.2 \%(11 / 42)$ were still indeterminate. New paraffin blocks were tested in three patients, of which one yielded a complete report. Repeat testing identified a pathogenic variant in three failed cases and four cases with low depth of coverage. Of interest, one sample had low coverage depth in exons 22-23 in BRCA1 in both initial and repeat tests, which was confirmed using a second independent methodology (following 
enrichment using the Illumina TruSight Rapid Capture Kit) [37] to be a likely pathogenic deletion of exons 22-23.

Thus, overall success rates based on the 291 samples were as follows: complete reports issued in most cases $(86.3 \%, 251 / 291)$, failed reports in $5.1 \%(15 / 291)$, while $8.6 \%(25 / 291)$ of cases were still considered indeterminate (Figure 2). Of these 25 patients, 15 had $<5$ exons with low coverage, 6 had 5-9 exons with low coverage, and 4 had $\geq 10$ exons with low coverage; the remaining exons were successfully sequenced.

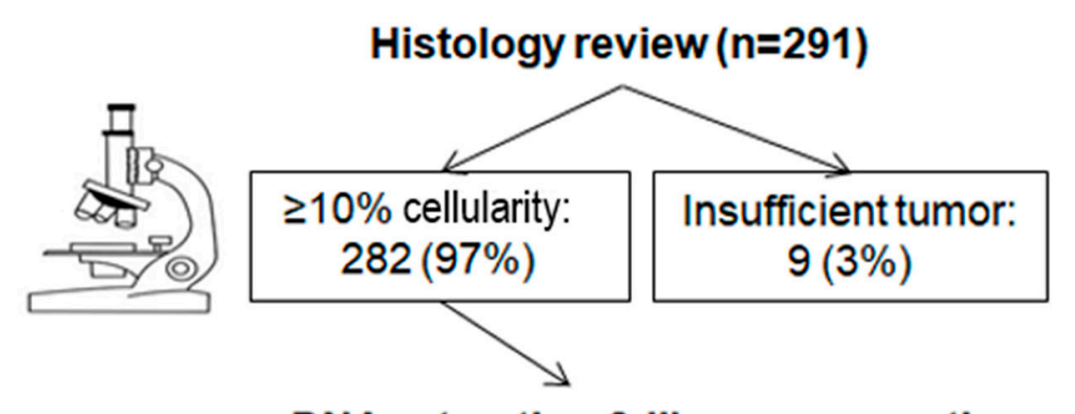

\section{DNA extraction \& library preparation}
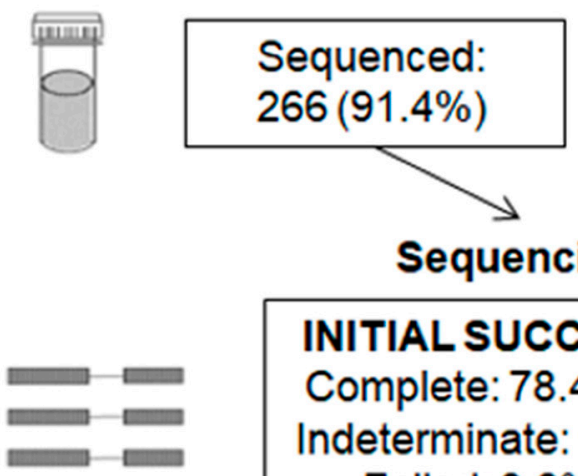

Failed (DNA quality): $16(5.5 \%)$

\section{Sequencing}

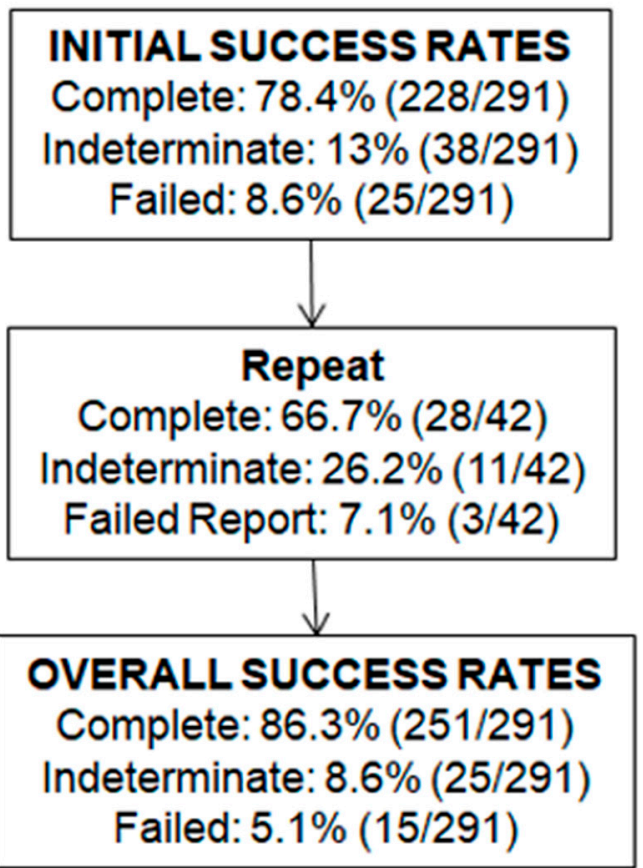

Figure 1. Schematic summary of success rates of tumor $B R C A$ analysis. Complete report: all exons of $B R C A 1$ and $B R C A 2$ sequenced; indeterminate report: $\geq 1$ exon of $B R C A 1$ and/or BRCA2 with low coverage depth or pathogenic or likely pathogenic variants below the limit of detection; failed report: unsuccessful BRCA analysis. 


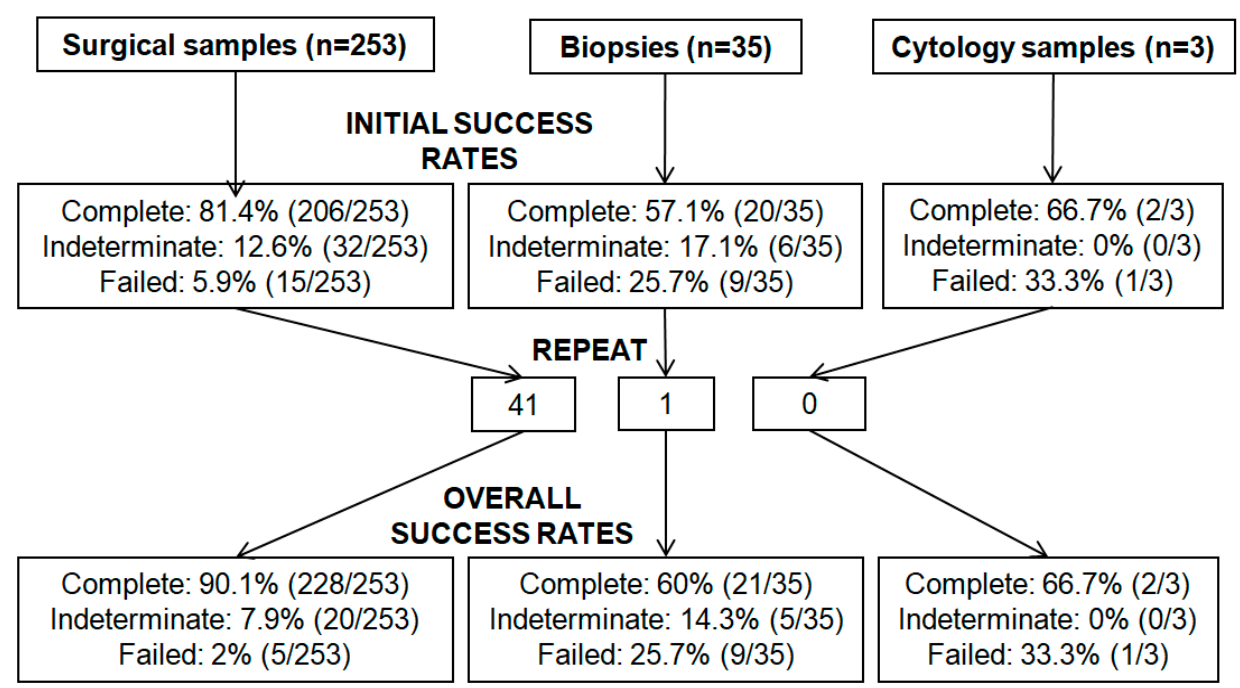

Figure 2. Success rates of tumor $B R C A$ analysis by specimen type. Complete report: all exons of $B R C A 1$ and $B R C A 2$ sequenced; indeterminate report: $\geq 1$ exon of $B R C A 1$ and/or BRCA2 with low coverage depth or pathogenic or likely pathogenic variants below the limit of detection; failed report: unsuccessful BRCA analysis.

\subsection{Predictors of Successful Tumor BRCA Analysis}

We next assessed how sample type, tumor cellularity, tumor size, neoadjuvant chemotherapy or age of paraffin blocks affected the rates of successful tumor $B R C A$ analysis. Detailed analysis of failure rates based on tumor cellularity and tumor size showed higher rates of failed reports among samples with lower tumor cellularity and smaller tumors. More specifically, failure rates were $4 \%(9 / 226)$ in samples with $\geq 50 \%$ cellularity, $15.2 \%$ (7/46) in samples with cellularity $>10 \%$ but $<50 \%$, and $47.4 \%$ $(9 / 19)$ in samples with $\leq 10 \%$ cellularity $(p<0.0001)$. When rates of successful tumor BRCA analysis were analyzed by tumor size, failure rates were $6.6 \%$ (17/259) in samples measuring $\geq 10 \mathrm{~mm}, 7.1 \%$ $(1 / 14)$ in samples measuring $5-9 \mathrm{~mm}$, and $38.9 \%(7 / 18)$ in samples measuring $\leq 4 \mathrm{~mm}(p<0.0001)$. Comparison of specimen types demonstrated a failure rate of $25.7 \%(9 / 35)$ in biopsies, $33.3 \%(1 / 3)$ in cytology specimens and 5.9\% (15/253) in surgical samples $(p=0.001)$. There was no association with post-neoadjuvant chemotherapy, age of the paraffin blocks tested or referring site $(p \geq 0.396)$ (Table 2$)$. The mutation rate was 13\% (19/144) in patients diagnosed before 2018 versus 20\% (29/147) for patients diagnosed after 2018 (Fisher's $p=0.16$ ).

Table 2. Summary of initial success rates of $B R C A 1 / 2$ sequencing based on clinical-pathologic variables.

\begin{tabular}{|c|c|c|c|c|c|c|}
\hline \multicolumn{2}{|c|}{ Clinical-Pathologic Variables } & \multirow{2}{*}{\begin{tabular}{|c|} 
Complete \\
$206(81.4 \%)$
\end{tabular}} & \multirow{2}{*}{$\begin{array}{c}\text { Failed } \\
15(5.9 \%)\end{array}$} & Indeterminate & \multirow{2}{*}{$\begin{array}{c}\text { Total } \\
253(87 \%)\end{array}$} & \multirow[t]{2}{*}{$p$-Value (Pearson Chi-Square) } \\
\hline \multirow{3}{*}{ Sample type } & Surgical & & & $32(12.7 \%)$ & & \\
\hline & Biopsy & $20(57.1 \%)$ & $9(25.7 \%)$ & $6(17.2 \%)$ & $35(12 \%)$ & \multirow[t]{2}{*}{0.001} \\
\hline & Cytology & $2(66.7 \%)$ & $1(33.3 \%)$ & 0 & $3(1 \%)$ & \\
\hline \multirow{3}{*}{ Tumor cellularity } & $\geq 50 \%$ & $185(81.9 \%)$ & $9(4.0 \%)$ & 32 (14.1\%) & $226(77.7 \%)$ & \multirow{3}{*}{$<0.0001$} \\
\hline & $>10 \%$ to $<50 \%$ & $34(73.9 \%)$ & $7(15.2 \%)$ & $5(10.9 \%)$ & $46(15.8 \%)$ & \\
\hline & $\leq 10 \%$ & $9(47.4 \%)$ & $9(47.4 \%)^{*}$ & $1(5.2 \%)$ & $19(6.5 \%)$ & \\
\hline \multirow{3}{*}{ Tumor size } & $\geq 10 \mathrm{~mm}$ & $206(79.5 \%)$ & $17(6.6 \%)$ & 36 (13.9\%) & $259(89 \%)$ & \multirow{3}{*}{$<0.0001$} \\
\hline & $5-9 \mathrm{~mm}$ & $13(92.9 \%)$ & $1(7.1 \%)$ & 0 & $14(4.8 \%)$ & \\
\hline & $\leq 4 \mathrm{~mm}$ & $9(50.0 \%)$ & $7(38.9 \%)$ & $2(11.1 \%)$ & $18(6.2 \%)$ & \\
\hline \multirow{2}{*}{ Chemotherapy } & Yes & $64(75.3 \%)$ & $9(10.6 \%)$ & $12(14.1 \%)$ & $85(29.2 \%)$ & \multirow{2}{*}{0.669} \\
\hline & No & $164(79.6 \%)$ & $16(7.8 \%)$ & $26(12.6 \%)$ & $206(70.8 \%)$ & \\
\hline \multirow{2}{*}{ Age of tissue block, years } & $<3$ & $111(75.5 \%)$ & $13(8.8 \%)$ & $23(15.7 \%)$ & $147(50.5 \%)$ & \multirow[b]{2}{*}{0.396} \\
\hline & $\geq 3$ & $117(81.3 \%)$ & $12(8.3 \%)$ & $15(10.4 \%)$ & $144(49.5 \%)$ & \\
\hline \multicolumn{2}{|l|}{ Total } & $228(78.4 \%)$ & $25(8.6 \%)$ & $38(13.0 \%)$ & $291(100 \%)$ & \\
\hline
\end{tabular}




\subsection{Histologic Analysis}

We retrospectively assessed histologic variables previously reported to be predictive of $B R C A 1 / 2$ status in surgical specimens from 172 chemotherapy naïve patients. These variables included the Solid, pseudo-Endometrioid and Transitional cell-like (SET) features, necrosis, grade 3 nuclei, abundant tumor-infiltrating lymphocytes (TILs) and metastases with pushing or micropapillary growth patterns. Formal statistical analysis was underpowered due to the small number of $B R C A 1$ and $B R C A 2$ mutant samples; however, histologic features in tissue samples with and without $B R C A$ mutations are summarized in Table 3.

Table 3. Summary of histologic features associated with $B R C A 1 / 2$ mutations in surgical specimens from a cohort of 172 chemotherapy-naïve patients.

\begin{tabular}{|c|c|c|c|c|c|}
\hline Histologic Features & Mutation Total & $\begin{array}{c}\text { BRCA1 } \\
\text { Mutation }\end{array}$ & $\begin{array}{c}\text { BRCA2 } \\
\text { Mutation }\end{array}$ & $\begin{array}{c}\text { No } \\
\text { Mutation }\end{array}$ & Total \\
\hline \multicolumn{6}{|l|}{ SET features } \\
\hline $\mathrm{E}$ & $11(32.4 \%)$ & $7(35 \%)$ & $4(28.6 \%)$ & $21(15.2 \%)$ & $32(18.6 \%)$ \\
\hline $\mathrm{T}$ & $4(11.8 \%)$ & 0 & $4(28.6 \%)$ & $2(1.4 \%)$ & $6(3.5 \%)$ \\
\hline All 3 features & $2(5.9 \%)$ & 0 & $2(14.3 \%)$ & $2(1.4 \%)$ & $4(2.3 \%)$ \\
\hline Necrosis & $27(79.4 \%)$ & $18(90 \%)$ & $9(64.3 \%)$ & $93(67.4 \%)$ & $120(69.8 \%)$ \\
\hline Grade 3 nuclei & $15(44.1 \%)$ & $11(55 \%)$ & $4(28.6 \%)$ & $79(57.2 \%)$ & $94(54.6 \%)$ \\
\hline TILs & $5(14.7 \%)$ & $2(10 \%)$ & $3(21.4 \%)$ & $14(10.1 \%)$ & $19(11 \%)$ \\
\hline $\begin{array}{l}\text { Metastasis with pushing or micropapillary } \\
\text { pattern }\end{array}$ & $3(8.8 \%)$ & $2(10 \%)$ & $1(7.1 \%)$ & $4(2.9 \%)$ & $7(4.1 \%)$ \\
\hline
\end{tabular}

SET, Solid, pseudo-Endometrioid and Transitional cell-like; TILs, tumor-infiltrating lymphocytes.

\subsection{Clinically Significant BRCA Mutations}

Pathogenic or likely pathogenic variants were identified in $17.4 \%(48 / 276)$ of complete and indeterminate cases, including $B R C A 1$ variants in 30 patients and $B R C A 2$ variants in 18 patients (Tables 4 and S1). The most common type of mutations was substitutions (23/48, 47.9\%). Of these, 12 created a premature stop codon, 7 were splicing alterations, and 4 were missense mutations. The remaining mutations were small deletions $(39.6 \%, 19 / 48)$, small duplications $(6.2 \%, 3 / 48)$, combined indels $(4.2 \%, 2 / 48)$, and small insertions $(2.1 \%, 1 / 48)$, all of which resulted in a frameshift (Table 4$)$. Most patients with mutations $(60.4 \%, 29 / 48)$ were 60 years or older, including 16 patients aged 70-79 and 13 patients aged $60-69$. Only eight patients $(16.7 \%)$ were $40-49$ years of age.

In addition, our study identified 33 variants of uncertain significance (VUS) in 27 patients, including 23 patients with 1 VUS, 3 patients with 2 VUS, and 1 patient with 4 VUS. Five of the 23 patients with 1 VUS also had a pathogenic variant. Almost all VUS were substitution variants $(97 \%$, 32/33), including 26 missense variants, 3 silent variants, 2 splicing alterations, 1 variant located in the $5^{\prime}$ untranslated region, and 1 in-frame deletion. Unlike pathogenic variants, VUS were more common in BRCA2 $(69.7 \%, 23 / 33)$ than BRCA1 $(33.3 \%, 11 / 33)$ (Table S2).

\subsection{Loss of heterozygosity ( $\mathrm{LOH})$ Analysis}

This molecular test was evaluated for copy number variant detection by way of assessing allelic imbalances in tumors for individual variants, although amplicon sequencing may not be the best approach for the detection of copy number alterations or $\mathrm{LOH}$. Tumors were considered $\mathrm{LOH}$ positive if there was an allelic imbalance of two or more variants in the same gene with allele frequencies between 5 and $45 \%$ or 55 and $95 \%$, regardless of the presence of a pathogenic variant. Among the 276 patients with complete or indeterminate $B R C A 1 / 2$ sequencing results, $204(73.9 \%)$ had $\mathrm{LOH}$ in either $B R C A 1$ only $(59,29 \%), B R C A 2$ only $(78,38.2 \%)$, or both $B R C A 1$ and $B R C A 2(67,32.8 \%)$. By this definition, 39 of $48(81.3 \%)$ subjects with a pathogenic variant had LOH. Among these, $31(79.5 \%)$ 
tumors showed $\mathrm{LOH}$ in the same gene as the mutation with $14(35.9 \%)$ in $B R C A 1$ and $17(43.6 \%)$ in $B R C A 2 ; 8(20.5 \%)$ samples had LOH in the non-mutated BRCA gene (Table S2). By applying this method of determining $\mathrm{LOH}$, we assessed whether or not the $\mathrm{LOH}$ occurred at the same allele as the pathogenic variant in order to investigate bi-allelic inactivation. Among the 48 pathogenic variants, $29(60.4 \%)$ had an allele frequency greater than 0.55 . Of these, $11(37.9 \%)$ had another variant with an allele frequency below $0.45 ; 10(34.5 \%)$ had another variant with an allele frequency above 0.55 , but no variant below $0.45 ; 8(27.6 \%)$ did not have any other variants in the same gene and did not meet $\mathrm{LOH}$ criteria defined here as allelic imbalance in at least two variants.

Table 4. Summary of pathogenic and likely pathogenic BRCA variants identified.

\begin{tabular}{|c|c|c|c|c|c|c|c|c|}
\hline No & Exon & Variant & $\begin{array}{c}\text { Allele } \\
\text { Frequency }\end{array}$ & Cellularity, \% & Amino Acid Change & $\begin{array}{l}\text { Mutation } \\
\text { Type }\end{array}$ & $\begin{array}{c}\text { Mutation } \\
\text { Effect }\end{array}$ & LOH Status \\
\hline 1 & $22-23$ & c.5333-?_5467+?del & Unknown & 70 & p.(Asp1778_His1822del) & Deletion & Frameshift & None \\
\hline 3 & 11 & c. $3607 \mathrm{C}>\mathrm{T}$ & 0.541 & 80 & p. $\left(\operatorname{Arg} 1203^{*}\right)$ & Substitution & Stop codon & $B R C A 2$ only \\
\hline 4 & 15 & c.4485-10_4491del & 0.362 & 80 & p.(Arg1495fs) & Deletion & Frameshift & None \\
\hline 5 & 19 & c. $5154 \mathrm{G}>\mathrm{A}$ & 0.050 & 90 & p. $\left(\operatorname{Trp} 1718^{*}\right)$ & Substitution & Stop codon & $B R C A 1$ and $B R C A 2$ \\
\hline 6 & 11 & c.1387_1390delinsGAAAG & 0.855 & 80 & p.(Lys463Glufs*17) & Indel & Frameshift & $B R C A 1$ and $B R C A 2$ \\
\hline 9 & 5 & c. $212+3 A>G$ & 0.802 & 70 & p.? & Substitution & Splicing & $B R C A 1$ and $B R C A 2$ \\
\hline 10 & 11 & c.1961del & 0.631 & 80 & p.(Lys654fs) & Deletion & Frameshift & $B R C A 2$ only \\
\hline 11 & 24 & c. $5497 \mathrm{G}>\mathrm{A}$ & 0.927 & 80 & p.(Val1833Met) & Substitution & Missense & $B R C A 1$ and $B R C A 2$ \\
\hline 12 & 11 & c. $2365 \mathrm{del}$ & 0.642 & 70 & p.(Ser789Alafs*3) & Deletion & Frameshift & $B R C A 2$ only \\
\hline 13 & 11 & c. $2827 \mathrm{~A}>\mathrm{T}$ & 0.304 & 80 & p. $\left(\right.$ Lys $\left.943^{*}\right)$ & Substitution & Stop codon & $B R C A 1$ only \\
\hline 14 & 11 & c.3225_3226del & 0.685 & 80 & p.(Asn1075fs) & Deletion & Frameshift & $B R C A 1$ and $B R C A 2$ \\
\hline 15 & 11 & c. $2188 \mathrm{G}>\mathrm{T}$ & 0.800 & 80 & p. $($ Glu730*) & Substitution & Stop codon & $B R C A 1$ and $B R C A 2$ \\
\hline 20 & 11 & c. $2269 \mathrm{del}$ & 0.173 & 10 & p.(Val757fs) & Deletion & Frameshift & None \\
\hline 21 & 11 & c.3481_3491del & 0.585 & 70 & p.(Glu1161fs) & Deletion & Frameshift & $B R C A 2$ only \\
\hline 22 & 21 & c. $5324 \mathrm{~T}>\mathrm{G}$ & 0.628 & 80 & p.(Met1775Arg) & Substitution & Missense & $B R C A 1$ and $B R C A 2$ \\
\hline 23 & 14 & c. $4372 \mathrm{C}>\mathrm{T}$ & 0.154 & 70 & p. $\left(\mathrm{G} \ln 1458^{*}\right)$ & Substitution & Stop codon & None \\
\hline 24 & 9 & c. $593+1 \mathrm{G}>\mathrm{A}$ & 0.051 & 80 & p.? & Substitution & Splicing & BRCA1 only \\
\hline 25 & 11 & c. $1603 \mathrm{G}>\mathrm{T}$ & 0.715 & 80 & p. $\left(\right.$ Gly $\left.535^{*}\right)$ & Substitution & Stop codon & $B R C A 1$ only \\
\hline 26 & 11 & c.1390_1391insG & 0.674 & 80 & p.(Thr464Serfs*16) & Insertion & Frameshift & BRCA1 only \\
\hline 27 & 11 & c.1504_1508del & 0.743 & 80 & p.(Leu502Alafs*2) & Deletion & Frameshift & $B R C A 1$ and $B R C A 2$ \\
\hline 28 & 16 & c. $4689 \mathrm{C}>\mathrm{G}$ & 0.818 & 70 & p. $($ Tyr1563*) & Substitution & Stop codon & $B R C A 1$ and $B R C A 2$ \\
\hline 29 & 19 & c. $5193+1 \mathrm{G}>\mathrm{T}$ & 0.614 & 90 & p.? & Substitution & Splicing & BRCA1 only \\
\hline 30 & 21 & c.5296del & 0.391 & 90 & p.(Ile1766Serfs*27) & Deletion & Frameshift & $B R C A 1$ only \\
\hline \multicolumn{9}{|l|}{$B R C A 2$} \\
\hline 31 & 11 & c. $4321 \mathrm{G}>\mathrm{T}$ & 0.616 & 60 & p.(Glu1441*) & Substitution & Stop codon & $B R C A 2$ only \\
\hline 32 & 11 & c.5238dupT & 0.681 & 50 & p.(Asn1747fs) & Duplication & Frameshift & $B R C A 2$ only \\
\hline 42 & 11 & c.6267_6269delinsC & 0.848 & 40 & p.(His2090fs) & Indel & Frameshift & $B R C A 1$ and $B R C A 2$ \\
\hline 43 & 11 & c. $4631 \mathrm{del}$ & 0.869 & 80 & p.(Asn1544fs) & Deletion & Frameshift & $B R C A 2$ only \\
\hline 44 & 11 & c.3545_3546delTT & 0.813 & 40 & p.(Phe1182fs) & Deletion & Frameshift & None \\
\hline 45 & 24 & c. $9154 \mathrm{C}>\mathrm{T}$ & 0.341 & 80 & p.(Arg3052Trp) & Substitution & Missense & $B R C A 1$ and $B R C A 2$ \\
\hline 46 & 10 & c.1859_1865del & 0.645 & 90 & p.(Phe620*) & Deletion & Frameshift & $B R C A 2$ only \\
\hline 47 & 11 & c.5351dup & 0.293 & 80 & p.(Asn1784Lysfs*3) & Duplication & Frameshift & $B R C A 2$ only \\
\hline 48 & 11 & c. $3187 \mathrm{C}>\mathrm{T}$ & 0.057 & 20 & p. $\left(\mathrm{G} \ln 1063^{*}\right)$ & Substitution & Stop codon & None \\
\hline
\end{tabular}

$\mathrm{LOH}$, loss of heterozygosity

\section{Discussion}

Our cohort consists of 291 HGSC patients who underwent tumor BRCA1/2 testing between 1 September 2018 and 31 May 2019 in our laboratory to determine eligibility for PARP inhibitor therapy. Tumor BRCA1/2 variant status was determined for 276 patients (251 complete reports with fully sequenced $B R C A 1$ and $B R C A 2$ genes, 25 indeterminate reports with at least one failed exon), of which $17.4 \%(48 / 276)$ had a pathogenic/likely pathogenic variant and $8.3 \%(23 / 276)$ carried a VUS. The overall mutation rate of $17.4 \%$ in our study may be on the lower end of the spectrum but appears 
comparable to the combined germline and somatic mutation rate of $16.7-28 \%$ reported in previous studies $[7,10,12,14,35]$. We hypothesize that this is primarily due to ascertainment bias as some patients diagnosed before 2018 may have already been tested negative for a germline $B R C A$ mutation. In support of our hypothesis, we found that the pathogenic/likely pathogenic mutation rate for patients diagnosed before 2018 was 13\%, whereas the diagnostic yield was 20\% after 2018. Although not statistically significant, the post-2018 rate is more consistent with what we had previously observed in the hereditary breast and ovarian cancer germline genetic testing program in Ontario [38] as well as with the existing literature $[7,10,12,35]$. However, given that the molecular test does not distinguish between somatic or germline mutations, we were not able to assess the actual somatic mutation rate in this cohort by way of ruling out germline variation.

The FFPE tumor samples were first assessed by analyzing tumor cellularity and tumor size. In general, we observed that samples with higher tumor cellularity and larger tumors had better outcomes of tumor $B R C A$ analysis, with failure rates at $4 \%$ in samples with $\geq 50 \%$ cellularity versus $47.4 \%$ in samples with $\leq 10 \%$ cellularity, and $6.6 \%$ in samples measuring $\geq 10 \mathrm{~mm}$ versus $38.9 \%$ in samples measuring $\leq 4 \mathrm{~mm}(p<0.0001)$. In addition, surgical specimens had better analysis yield compared to biopsies and cytology specimens with failures rates of 5.9\%, 25.7\% and 33.3\%, respectively $(p=0.001)$, although only three cytology samples were included in the study. Interestingly, neoadjuvant chemotherapy or age of paraffin blocks did not affect the failure rate. These results support the use of FFPE samples with high tumor cellularity. In addition, samples measuring $<5 \mathrm{~mm}$ in size have an almost $40 \%$ probability of failure, highlighting the importance of recording tumor size in addition to cellularity. It is also worth noting that despite this association between low tumor cellularity and small tumor size with higher failure rates, samples with $10 \%$ tumor cellularity (the lowest eligible cellularity) and those measuring $\leq 4 \mathrm{~mm}$ were still successfully sequenced. This indicates that tumors measuring $\leq 4 \mathrm{~mm}$ or tumors with $10 \%$ cellularity may still yield sufficient DNA for sequencing, although a higher proportion of failures would be expected. Thus, sequencing may be attempted on these samples if and when more optimal specimens are not available.

In order to maximize diagnostic yield, a second sample, if available, was sequenced if the first test failed or resulted in an indeterminate report with variants below the LOD or low coverage depth in at least one exon. A report with low coverage depth was considered indeterminate because there may be pathogenic variants within the exons of low coverage that were not detected. Of the 291 patients, 8.6\% had failed reports, and 13\% had indeterminate reports following the first test per patient. Among 42 patients that had a second sample tested, complete reports were successfully generated in $66.7 \%$. A pathogenic variant was also identified in seven patients (three failed, four with low depth coverage), demonstrating high value in repeating previously failed samples as well as samples with low depth coverage. Only three repeats were done on a different tissue block, suggesting that a new block may not be necessary. In summary, after repeat testing, the proportion of conclusive reports increased from $78.4 \%$ to $86.3 \%$, while the number of indeterminate reports decreased from $13 \%$ to $8.6 \%$, demonstrating that repeat testing is an effective method of increasing diagnostic yield in a clinical setting for challenging tissues such as FFPE.

With the incorporation of $B R C A 1 / 2$ sequencing into HGSC treatment, it is of interest to associate histologic characteristics with $B R C A 1 / 2$ mutation status. Various histologic features have been reported to be predictive of $B R C A$ mutations including the presence of SET features, necrosis, grade 3 nuclei, tumor infiltrating lymphocytes and mitotic index as well as metastases with pushing or "medullary-like" invasion or infiltrative invasion composed exclusively of micropapillae [39-41]. Although the histologic criteria developed in previous studies have limited positive predictive value, they have been more effective at predicting the absence of $B R C A 1 / 2$ mutations with negative predictive value of $>95 \%[39,40]$. Our study was underpowered for formal statistical analysis. However, the aforementioned histologic features could be another tool used by clinicians to prioritize accessibility to BRCA1/2 testing in situations where this is necessary. 
$\mathrm{LOH}$ was not included in most clinical trials to determine if individuals with this type of genomic alteration might be responsive to PARP inhibitors [27,31,42-44], as LOH status is not considered to be the type of pathogenic variant that would be eligible for PARP inhibitors. We assessed LOH status for every patient based on allelic imbalances; however, it was not used for clinical decisions. In our study, $73.9 \%$ of patients had LOH which could be due to high genomic instability of HGSC. Some of the variants had low $(<10 \%)$ allele frequency even in tumors with $>80 \%$ cellularity and LOH. This could be explained as artifacts or low level somatic variation. Alternatively, if a non-tumor variant occurred in a sample with $80 \%$ cellularity as a heterozygote, the theoretical allelic fraction would be $10 \%$.

Previous studies have suggested that HGSC with retention of the normal BRCA1 or BRCA2 allele (absence of locus-specific LOH) may have lower HR deficiency scores compared with tumors with locus-specific LOH, and the latter may be used to predict primary resistance to PARP inhibitors in BRCA mutation carriers [45]. Although LOH was not investigated in clinical trials for PARP inhibitor therapy, BRCA wild-type patients with LOH were analyzed as a subgroup in the ARIEL 3 clinical trial for rucaparib and demonstrated improved progression free survival compared to placebo [46]. If LOH alone is sufficient for PARP inhibitors to be effective, treatment with PARP inhibitors could potentially be extended to $73.9 \%$ of patients in our study who tested positive for $\mathrm{LOH}$ based on our criteria. In theory, however, the effective mechanism of PARP inhibitors requires inactivation of both copies of either BRCA1 or BRCA2. This is supported by in vitro and in vivo studies that demonstrate mutated cells in the heterozygous state are significantly less responsive to PARP inhibitors compared to homozygous mutants [47-51]. Based on this theory, only patients with bi-allelic inactivation of $B R C A 1 / 2$ should be eligible, which would exclude the currently eligible hypothetical subset of patients who are heterozygous for a $B R C A 1 / 2$ mutation with no apparent inactivation of the second copy. We found that among the 48 patients with a BRCA mutation, 39 met our general criteria for LOH, but of these only 21 (43\%) had a pathogenic variant allele frequency above 0.55 that supported bi-allelic inactivation. These rates are considerably lower than previously reported rates of $84-100 \%$ of $\mathrm{LOH}$ in germline mutant $B R C A 1 / 2$ [45,52]. Two mutations had an allele frequency between 0.45 and 0.55 while the remaining 16 had an allele frequency below 0.45 . Some of these low frequency mutations may indicate mutations that were somatic in origin. Because LOH status was determined by a shift in allele frequency to 55-95\%, we could not determine if it was caused by deletion, mitotic recombination or gene conversion, or other more complex chromosomal alterations which could result in copy number abnormality or copy neutral LOH. We also did not assess other potential methods of gene inactivation such as promoter methylation which would be a valuable future addition to this test. Additionally, it is generally more difficult to detect large deletions in DNA extracted from FFPE tissue compared to germline DNA [32].

Given that tumor BRCA1/2 testing identifies both germline and somatic mutations, we endorse universal tumor testing in newly diagnosed HGSC patients. The universal tumor BRCA1/2 testing workflow has been shown to be a feasible, effective and robust option in daily pathology practice, and well perceived by gynecologists and patients [14]. It maximizes mutation detection rate (at least 16.7\% versus 9.5\% with universal genetic predisposition testing) and effectively identifies patients who are eligible for PARP inhibitor therapy. In addition, it may also serve as a screening tool to tailor genetic counseling and may improve uptake of genetic predisposition testing in HGSC patients [14]. It should also be noted that there are other genes in the HR family, such as ARID1A, ATM, ATRX, BAP1, BARD1, BLM, BRIP1, CHEK1/2, PALB2, RAD50, RAD51, RAD51B, EMSY, that may be recognized as eligibility criteria for PARP inhibitor therapy in the future [53-55]. Lastly, PARP inhibitors are increasingly being used for patients with platinum-sensitive HGSC regardless of BRCA status [56,57].

Our study has several limitations: (a) germline mutation status of individuals whose tumor tissues tested positive for a BRCA1/2 mutation was unknown; thus, it is unclear if the mutations detected were of germline or somatic origin (albeit this does not affect eligibility for PARP inhibitors); (b) many cases were referred with only one submitted paraffin block available for histologic review, introducing a selection bias and limiting our assessment of $B R C A$ mutation associated morphologic features. 


\section{Materials and Methods}

\subsection{Study Population and Reference Laboratory}

A total of 291 patients with HGSC underwent tumor BRCA testing in the Advanced Molecular Diagnostics laboratory at Mount Sinai Hospital between October 2018 and May 2019. Patient eligibility for tumor BRCA testing was determined based on the Ontario Ministry of Health and Long-Term Care and Cancer Care Ontario guidelines. This included patients diagnosed with HGSC of the ovarian, fallopian tube or primary peritoneal origin, whose BRCA mutation status was either unknown or potentially negative for germline testing at the time of testing. Patients who have previously tested positive for a germline $B R C A$ mutation were not eligible. Samples were received from 15 different hospitals including Sinai Health System. Germline BRCA status was not provided by referring clinicians. The study was approved by the Research Ethics Board (19-0071E).

The Advanced Molecular Diagnostics laboratory at Mount Sinai Hospital is accredited by the Institute of Quality Management in Healthcare (IQMH) to ISO 15189:2012/15190:2003. All tests were validated according to accepted practice guidelines for molecular genetic testing of the American College of Medical Genetics (ACMG), the College of American Pathologists (CAP), and the Clinical and Laboratory Standards Institute (CLSI).

\subsection{Tissue Samples and DNA Extraction}

Microscopic slides were reviewed to confirm the diagnosis of HGSC, determine tumor cellularity in increments of 10 and maximum linear dimension in millimeters, and circle tumor tissue. Slides from chemotherapy naïve patients were also reviewed by a single pathologist blinded to sequencing results (GT) for specific histologic features associated with BRCA mutations. Tumors were then macrodissected from six 10- $\mu \mathrm{m}$ FFPE tissue sections with a minimum tumor cellularity of $10 \%$. DNA was extracted from macrodissected tumor samples using the Qiagen QIAsymphony DSP DNA Mini Kit on the Qiagen QiaSymphony SP Automated DNA Extractor (Qiagen, Venlo, The Netherlands). The quantity and quality of the DNA was determined by fluorescent spectrophotometric analysis using Qubit (Thermofisher, Waltham, MA, USA).

\subsection{Library Preparation and Analysis}

The Illumina AmpliSeq Library PLUS for the BRCA Panel kit (Illumina, SanDiego, CA, USA) was used to prepare multiplex PCR libraries for DNA sequencing according to the manufacturer instructions. The minimum acceptable tumor cellularity was $10 \%$, while the minimum acceptable sample DNA Qubit concentration was $>0.01 \mathrm{ng} / \mu \mathrm{L}$ in order to proceed with library preparation. Analysis included all exonic regions and flanking intronic sequences $( \pm 15$ base pairs from the exon boundaries) of BRCA1 and BRCA2 genes. Amplicon coverage included two primer pools (Pool 1: 132 amplicons, Pool 2: 133 amplicons) that overlap all the exonic and flanking intronic regions of the BRCA1 and BRCA2 genes. After amplification, leftover primer sequences were digested and sequencing adapters were ligated to the amplicons. Libraries were amplified again, quantitated, normalized and pooled together for sequencing. A Qubit value of $0.37 \mathrm{ng} / \mu \mathrm{L}$ was required to achieve the normalized concentration $(2 \mathrm{nM})$ for sample pooling to avoid preferential sequence amplification. Twelve tumor samples per library were pooled and run on an Illumina MiSeq instrument using a v2 Micro cartridge. Paired end reads 150 bp in each direction was used for this test. For repeat testing, DNA was re-extracted from the same block or a new block.

Quality control measures were followed per the provincial laboratory accreditation standards for DNA transfer (to dilution tubes or plate) and the plates had two unique identifiers to label each sample. In addition, proficiency testing is performed several times per year both internally and through external programs to assess performance and quality of the test. 


\subsection{Bioinformatic Analysis}

Variant calling was performed using the DNA Amplicon Analysis Module V1.1.0 from Illumina with a minimum per base coverage of 500 reads. Quality metrics for each run were evaluated and needed to meet minimum acceptable threshold values based on prior clinically validated testing metrics. These are summarized as averages as follows: total Yield (G) of 1.81 (SD 0.1), number of reads passing filter (Reads PF) (M) of 5.75 (SD 0.32), Cluster Density (k/mm²) of 1153 (SD 89.85), Clusters Passing Filter of $91.9 \%$ (SD 2.78) and >Q30 of $94.4 \%$ (SD 0.8) (Table S3).

A minimum per base read depth 500X was required to pass filter; the LOD (limit of detection) was determined to be $5 \%$ and a minimum of $5 \%$ frequency of the alternative allele was required for reporting.

The analytical sensitivity was $>99 \%$ and specificity was $100 \%$ for DNA substitutions and small deletions or duplications (up to $5 \mathrm{bp}$ ) as well as exon-level or full gene deletions or duplications, as demonstrated during the validation process in our laboratory before using the test in the clinical setting. This test does not reliably detect chromosomal aberrations or rearrangements.

To identify deletions or loss of heterozygosity $(\mathrm{LOH})$, a comprehensive analysis of all variants in both $B R C A$ genes was used based on internal validation metrics. Ranges of variant frequencies for LOH were as follows: no evidence of $\mathrm{LOH}(45-55 \%)$, strong evidence of $\mathrm{LOH}(5-45 \%)(55-95 \%)$, and not informative evidence of $\mathrm{LOH}(0-5 \%)(95-100 \%)$. LOH was reported if 2 or more variants from the same gene had strong evidence of LOH (Tables S4,S5, Figure S1).

\subsection{Reporting and Variant Interpretation}

DNA variants were described using HGVS (Human Genome Variation Society) nomenclature and variant interpretation and classification was based on the American College of Medical Genetics and Genomics (ACMG) 2015 guidelines [58]. Pathogenic and likely pathogenic variants were reported as clinically significant. Variants of uncertain significance were also included in the report, while benign and likely benign variants were not included (workflow scheme in Figure 3). The report emphasized that the results were specific to tumor tissue and would not decipher between germline versus somatic mutations. Thus, genetic counselling and germline testing was recommended by the laboratory for individuals with a pathogenic or likely pathogenic variant.

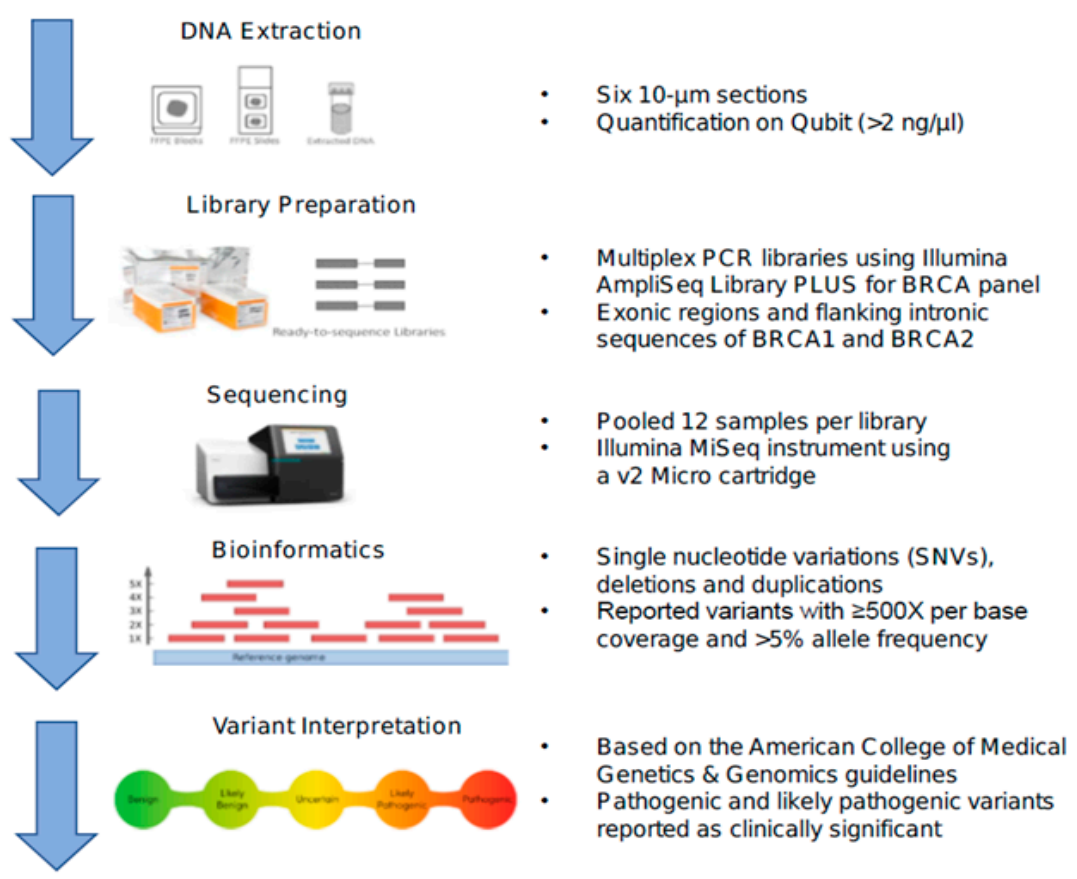

Figure 3. Schematic summary of laboratory workflow and analysis. 
If DNA extraction, library preparation or sequencing failed (defined as one or more exons falling below the target threshold coverage of 500X), a report was generated with a statement recommending repeat testing. If a pathogenic or likely pathogenic variant was identified, repeat testing was not recommended regardless of whether or not other exons met the target threshold coverage. Additionally, in samples with pathogenic or likely pathogenic variants that were below the LOD $(5 \%)$, an alternative sample was requested for confirmation testing. A maximum of two samples were tested for each patient.

\subsection{Statistical Analysis}

The significance of associations between variables was analyzed by using the chi-square test and Fisher's two-sided exact test. The software used was SPSS 25.0 for Windows. Probability values of $<0.05$ were considered significant.

\section{Conclusions}

This prospective analysis demonstrates that our $B R C A$-tumor testing workflow is effective in identifying individuals who may benefit from PARP inhibitor treatment, with success rates ranging from $78.4 \%$ on initial testing to $86.3 \%$ following repeat testing. Our study shows a $17.4 \%$ tumor $B R C A$ mutation rate, slightly lower compared to the literature most likely due to ascertainment bias of the studied population. Biopsy and cytology samples and post-chemotherapy specimens can be used, and optimal tumors measure $\geq 5 \mathrm{~mm}$ with at least greater than $10 \%$ cellularity. Variable quality of FFPE tissue remains a challenge but this was substantially alleviated through repeat testing with a $66.7 \%$ success rate. We also assessed $\mathrm{LOH}$ that may become a valuable diagnostic tool in the future if it is found to be clinically relevant in the context of PARP inhibitor therapy.

Supplementary Materials: The following are available online at http://www.mdpi.com/2072-6694/12/11/3468/s1, Figure S1: Validation data for LOH, Table S1: Detailed summary of pathogenic and likely pathogenic BRCA variants identified, Table S2: Summary of variants of unknown significance identified, Table S3: Metrics of an average sequencing run, Table S4: Summary of validation data for LOH, Table S5: Theorectical heterozygous variant fraction by tumor cellularity due to $\mathrm{LOH}$.

Author Contributions: Conceptualization, C.L., G.T.; methodology, A.P., A.W., G.C., J.L.-E., M.C.; validation, A.P., A.W., G.C., J.L.-E.; formal analysis, A.W., C.L., G.T., S.Y.; resources, D.Y., E.A., K.H., M.C.; data curation, A.W., C.L., G.T., S.Y.; writing—original draft preparation, C.L., G.T., S.Y.; writing—review and editing, C.L., G.T., J.L.-E. All authors have read and agreed to the published version of the manuscript.

Funding: This research received no external funding.

Acknowledgments: C.L. was a visiting scientist in the Department of Pathology and Laboratory Medicine, Mount Sinai Hospital and Women's College Hospital thanks to Salvador Madariaga (PRX18/00267) and M-BAE (BA18/00018) grants (Spanish Government) and was also Supported by the Carlos III National Health Institute funded by FEDER funds—a way to build Europe-(PI19/00553; PI16/00563 and CIBERONC).

Conflicts of Interest: The authors declare no conflict of interest.

\section{References}

1. Reid, B.M.; Permuth, J.B.; Sellers, T.A. Epidemiology of ovarian cancer: A review. Cancer Biol. Med. 2017, 14, 9-32. [CrossRef] [PubMed]

2. Gilks, C.B.; Ionescu, D.N.; Kalloger, S.E.; Kobel, M.; Irving, J.; Clarke, B.; Santos, J.; Le, N.; Moravan, V.; Swenerton, K.; et al. Tumor cell type can be reproducibly diagnosed and is of independent prognostic significance in patients with maximally debulked ovarian carcinoma. Hum. Pathol. 2008, 39, 1239-1251. [CrossRef] [PubMed]

3. Gockley, A.; Melamed, A.; Bregar, A.J.; Clemmer, J.T.; Birrer, M.; Schorge, J.O.; Del Carmen, M.G.; Rauh-Hain, J.A. Outcomes of Women with High-Grade and Low-Grade Advanced-Stage Serous Epithelial Ovarian Cancer. Obstet. Gynecol. 2017, 129, 439-447. [CrossRef] [PubMed]

4. Norquist, B.M.; Harrell, M.I.; Brady, M.F.; Walsh, T.; Lee, M.K.; Gulsuner, S.; Bernards, S.S.; Casadei, S.; Yi, Q.; Burger, R.A.; et al. Inherited Mutations in Women with Ovarian Carcinoma. JAMA Oncol. 2016, 2, 482-490. [CrossRef] [PubMed] 
5. Petrillo, M.; Marchetti, C.; De Leo, R.; Musella, A.; Capoluongo, E.; Paris, I.; Benedetti Panici, P.; Scambia, G.; Fagotti, A. BRCA mutational status, initial disease presentation, and clinical outcome in high-grade serous advanced ovarian cancer: A multicenter study. Am. J. Obstet. Gynecol. 2017, 217, 334.e1-334.e9. [CrossRef] [PubMed]

6. Zhang, S.; Royer, R.; Li, S.; McLaughlin, J.R.; Rosen, B.; Risch, H.A.; Fan, I.; Bradley, L.; Shaw, P.A.; Narod, S.A. Frequencies of BRCA1 and BRCA2 mutations among 1,342 unselected patients with invasive ovarian cancer. Gynecol. Oncol. 2011, 121, 353-357. [CrossRef]

7. Mafficini, A.; Simbolo, M.; Parisi, A.; Rusev, B.; Luchini, C.; Cataldo, I.; Piazzola, E.; Sperandio, N.; Turri, G.; Franchi, M.; et al. BRCA somatic and germline mutation detection in paraffin embedded ovarian cancers by next-generation sequencing. Oncotarget 2016, 7, 1076-1083. [CrossRef]

8. McAlpine, J.N.; Porter, H.; Kobel, M.; Nelson, B.H.; Prentice, L.M.; Kalloger, S.E.; Senz, J.; Milne, K.; Ding, J.; Shah, S.P.; et al. BRCA1 and BRCA2 mutations correlate with TP53 abnormalities and presence of immune cell infiltrates in ovarian high-grade serous carcinoma. Mod. Pathol. 2012, 25, 740-750. [CrossRef]

9. Pennington, K.P.; Walsh, T.; Harrell, M.I.; Lee, M.K.; Pennil, C.C.; Rendi, M.H.; Thornton, A.; Norquist, B.M.; Casadei, S.; Nord, A.S.; et al. Germline and somatic mutations in homologous recombination genes predict platinum response and survival in ovarian, fallopian tube, and peritoneal carcinomas. Clin. Cancer Res. 2014, 20, 764-775. [CrossRef]

10. Hennessy, B.T.; Timms, K.M.; Carey, M.S.; Gutin, A.; Meyer, L.A.; Flake, D.D., 2nd; Abkevich, V.; Potter, J.; Pruss, D.; Glenn, P.; et al. Somatic mutations in BRCA1 and BRCA2 could expand the number of patients that benefit from poly (ADP ribose) polymerase inhibitors in ovarian cancer. J. Clin. Oncol. 2010, 28, 3570-3576. [CrossRef]

11. Yang, D.; Khan, S.; Sun, Y.; Hess, K.; Shmulevich, I.; Sood, A.K.; Zhang, W. Association of BRCA1 and BRCA2 mutations with survival, chemotherapy sensitivity, and gene mutator phenotype in patients with ovarian cancer. JAMA 2011, 306, 1557-1565. [CrossRef] [PubMed]

12. Cancer Genome Atlas Research, N. Integrated genomic analyses of ovarian carcinoma. Nature 2011, 474, 609-615. [CrossRef] [PubMed]

13. De Jonge, M.M.; Ruano, D.; van Eijk, R.; van der Stoep, N.; Nielsen, M.; Wijnen, J.T.; Ter Haar, N.T.; Baalbergen, A.; Bos, M.; Kagie, M.J.; et al. Validation and Implementation of BRCA1/2 Variant Screening in Ovarian Tumor Tissue. J. Mol. Diagn. 2018, 20, 600-611. [CrossRef] [PubMed]

14. Vos, J.R.; Fakkert, I.E.; de Hullu, J.A.; van Altena, A.M.; Sie, A.S.; Ouchene, H.; Willems, R.W.; Nagtegaal, I.D.; Jongmans, M.C.J.; Mensenkamp, A.R.; et al. Universal Tumor DNA BRCA1/2 Testing of Ovarian Cancer: Prescreening PARPi Treatment and Genetic Predisposition. J. Natl. Cancer Inst. 2020, 112, 161-169. [CrossRef] [PubMed]

15. Wooster, R.; Neuhausen, S.L.; Mangion, J.; Quirk, Y.; Ford, D.; Collins, N.; Nguyen, K.; Seal, S.; Tran, T.; Averill, D.; et al. Localization of a breast cancer susceptibility gene, BRCA2, to chromosome 13q12-13. Science 1994, 265, 2088-2090. [CrossRef] [PubMed]

16. Friedman, L.S.; Ostermeyer, E.A.; Szabo, C.I.; Dowd, P.; Lynch, E.D.; Rowell, S.E.; King, M.C. Confirmation of BRCA1 by analysis of germline mutations linked to breast and ovarian cancer in ten families. Nat. Genet. 1994, 8, 399-404. [CrossRef]

17. Chapman, J.R.; Taylor, M.R.; Boulton, S.J. Playing the end game: DNA double-strand break repair pathway choice. Mol. Cell 2012, 47, 497-510. [CrossRef]

18. Venkitaraman, A.R. Cancer susceptibility and the functions of BRCA1 and BRCA2. Cell 2002, 108, $171-182$. [CrossRef]

19. Stoppa-Lyonnet, D. The biological effects and clinical implications of BRCA mutations: Where do we go from here? Eur. J. Hum. Genet. 2016, 24 (Suppl. 1), S3-S9. [CrossRef]

20. Ritterhouse, L.L.; Nowak, J.A.; Strickland, K.C.; Garcia, E.P.; Jia, Y.; Lindeman, N.I.; Macconaill, L.E.; Konstantinopoulos, P.A.; Matulonis, U.A.; Liu, J.; et al. Morphologic correlates of molecular alterations in extrauterine Mullerian carcinomas. Mod. Pathol. 2016, 29, 893-903. [CrossRef]

21. Alsop, K.; Fereday, S.; Meldrum, C.; deFazio, A.; Emmanuel, C.; George, J.; Dobrovic, A.; Birrer, M.J.; Webb, P.M.; Stewart, C.; et al. BRCA mutation frequency and patterns of treatment response in BRCA mutation-positive women with ovarian cancer: A report from the Australian Ovarian Cancer Study Group. J. Clin. Oncol. 2012, 30, 2654-2663. [CrossRef] [PubMed] 
22. Yang, S.Y.C.; Lheureux, S.; Karakasis, K.; Burnier, J.V.; Bruce, J.P.; Clouthier, D.L.; Danesh, A.; Quevedo, R.; Dowar, M.; Hanna, Y.; et al. Landscape of genomic alterations in high-grade serous ovarian cancer from exceptional long- and short-term survivors. Genome Med. 2018, 10, 81. [CrossRef] [PubMed]

23. Sisay, M.; Edessa, D. PARP inhibitors as potential therapeutic agents for various cancers: Focus on niraparib and its first global approval for maintenance therapy of gynecologic cancers. Gynecol. Oncol. Res. Pract. 2017, 4, 18. [CrossRef] [PubMed]

24. McLachlan, J.; George, A.; Banerjee, S. The current status of PARP inhibitors in ovarian cancer. Tumori J. 2016, 102, 433-440. [CrossRef] [PubMed]

25. Wang, Y.Q.; Wang, P.Y.; Wang, Y.T.; Yang, G.F.; Zhang, A.; Miao, Z.H. An Update on Poly(ADP-ribose)polymerase-1 (PARP-1) Inhibitors: Opportunities and Challenges in Cancer Therapy. J. Med. Chem. 2016, 59, 9575-9598. [CrossRef] [PubMed]

26. Papa, A.; Caruso, D.; Strudel, M.; Tomao, S.; Tomao, F. Update on Poly-ADP-ribose polymerase inhibition for ovarian cancer treatment. J. Transl. Med. 2016, 14, 267. [CrossRef]

27. Ledermann, J.; Harter, P.; Gourley, C.; Friedlander, M.; Vergote, I.; Rustin, G.; Scott, C.L.; Meier, W.; Shapira-Frommer, R.; Safra, T.; et al. Olaparib maintenance therapy in patients with platinum-sensitive relapsed serous ovarian cancer: A preplanned retrospective analysis of outcomes by BRCA status in a randomised phase 2 trial. Lancet Oncol. 2014, 15, 852-861. [CrossRef]

28. Pujade-Lauraine, E.; Ledermann, J.A.; Selle, F.; Gebski, V.; Penson, R.T.; Oza, A.M.; Korach, J.; Huzarski, T.; Poveda, A.; Pignata, S.; et al. Olaparib tablets as maintenance therapy in patients with platinum-sensitive, relapsed ovarian cancer and a BRCA1/2 mutation (SOLO2/ENGOT-Ov21): A double-blind, randomised, placebo-controlled, phase 3 trial. Lancet Oncol. 2017, 18, 1274-1284. [CrossRef]

29. Mirza, M.R.; Monk, B.J.; Herrstedt, J.; Oza, A.M.; Mahner, S.; Redondo, A.; Fabbro, M.; Ledermann, J.A.; Lorusso, D.; Vergote, I.; et al. Niraparib Maintenance Therapy in Platinum-Sensitive, Recurrent Ovarian Cancer. N. Engl. J. Med. 2016, 375, 2154-2164. [CrossRef]

30. Dougherty, B.A.; Lai, Z.; Hodgson, D.R.; Orr, M.C.M.; Hawryluk, M.; Sun, J.; Yelensky, R.; Spencer, S.K.; Robertson, J.D.; Ho, T.W.; et al. Biological and clinical evidence for somatic mutations in BRCA1 and BRCA2 as predictive markers for olaparib response in high-grade serous ovarian cancers in the maintenance setting. Oncotarget 2017, 8, 43653-43661. [CrossRef]

31. Moore, K.; Colombo, N.; Scambia, G.; Kim, B.G.; Oaknin, A.; Friedlander, M.; Lisyanskaya, A.; Floquet, A.; Leary, A.; Sonke, G.S.; et al. Maintenance Olaparib in Patients with Newly Diagnosed Advanced Ovarian Cancer. N. Engl. J. Med. 2018, 379, 2495-2505. [CrossRef] [PubMed]

32. Capoluongo, E.; Ellison, G.; Lopez-Guerrero, J.A.; Penault-Llorca, F.; Ligtenberg, M.J.L.; Banerjee, S.; Singer, C.; Friedman, E.; Markiefka, B.; Schirmacher, P.; et al. Guidance Statement On BRCA1/2 Tumor Testing in Ovarian Cancer Patients. Semin. Oncol. 2017, 44, 187-197. [CrossRef] [PubMed]

33. Wallace, A.J. New challenges for BRCA testing: A view from the diagnostic laboratory. Eur J. Hum. Genet. 2016, 24 (Suppl. 1), S10-S18. [CrossRef] [PubMed]

34. Wong, S.Q.; Li, J.; Tan, A.Y.; Vedururu, R.; Pang, J.M.; Do, H.; Ellul, J.; Doig, K.; Bell, A.; MacArthur, G.A.; et al. Sequence artefacts in a prospective series of formalin-fixed tumours tested for mutations in hotspot regions by massively parallel sequencing. BMC Med. Genom. 2014, 7, 23. [CrossRef] [PubMed]

35. Koczkowska, M.; Zuk, M.; Gorczynski, A.; Ratajska, M.; Lewandowska, M.; Biernat, W.; Limon, J.; Wasag, B. Detection of somatic BRCA1/2 mutations in ovarian cancer-Next-generation sequencing analysis of 100 cases. Cancer Med. 2016, 5, 1640-1646. [CrossRef]

36. Fumagalli, C.; Tomao, F.; Betella, I.; Rappa, A.; Calvello, M.; Bonanni, B.; Bernard, L.; Peccatori, F.; Colombo, N.; Viale, G.; et al. Tumor BRCA Test for Patients with Epithelial Ovarian Cancer: The Role of Molecular Pathology in the Era of PARP Inhibitor Therapy. Cancers (Basel) 2019, 11, 1641. [CrossRef]

37. Lerner-Ellis, J.; Mighton, C.; Lazaro, C.; Watkins, N.; Di Gioacchino, V.; Wong, A.; Chang, M.C.; Charames, G.S. Multigene panel testing for hereditary breast and ovarian cancer in the province of Ontario. J. Cancer Res. Clin. Oncol. 2020. [CrossRef]

38. Finch, A.; Bacopulos, S.; Rosen, B.; Fan, I.; Bradley, L.; Risch, H.; McLaughlin, J.R.; Lerner-Ellis, J.; Narod, S.A. Preventing ovarian cancer through genetic testing: A population-based study. Clin. Genet. 2014, 86, 496-499. [CrossRef]

39. Fujiwara, K. Three ongoing intraperitoneal chemotherapy trials in ovarian cancer. J. Gynecol. Oncol. 2012, 23, 75-77. [CrossRef] 
40. Soslow, R.A.; Han, G.; Park, K.J.; Garg, K.; Olvera, N.; Spriggs, D.R.; Kauff, N.D.; Levine, D.A. Morphologic patterns associated with BRCA1 and BRCA2 genotype in ovarian carcinoma. Mod. Pathol. 2012, 25, 625-636. [CrossRef]

41. Reyes, M.C.; Arnold, A.G.; Kauff, N.D.; Levine, D.A.; Soslow, R.A. Invasion patterns of metastatic high-grade serous carcinoma of ovary or fallopian tube associated with BRCA deficiency. Mod. Pathol. 2014, 27, 1405-1411. [CrossRef] [PubMed]

42. Ledermann, J.; Harter, P.; Gourley, C.; Friedlander, M.; Vergote, I.; Rustin, G.; Scott, C.; Meier, W.; Shapira-Frommer, R.; Safra, T.; et al. Olaparib maintenance therapy in platinum-sensitive relapsed ovarian cancer. N. Engl. J. Med. 2012, 366, 1382-1392. [CrossRef] [PubMed]

43. Ledermann, J.A.; Harter, P.; Gourley, C.; Friedlander, M.; Vergote, I.; Rustin, G.; Scott, C.; Meier, W.; Shapira-Frommer, R.; Safra, T.; et al. Overall survival in patients with platinum-sensitive recurrent serous ovarian cancer receiving olaparib maintenance monotherapy: An updated analysis from a randomised, placebo-controlled, double-blind, phase 2 trial. Lancet Oncol. 2016, 17, 1579-1589. [CrossRef]

44. Kaufman, B.; Shapira-Frommer, R.; Schmutzler, R.K.; Audeh, M.W.; Friedlander, M.; Balmana, J.; Mitchell, G.; Fried, G.; Stemmer, S.M.; Hubert, A.; et al. Olaparib monotherapy in patients with advanced cancer and a germline BRCA1/2 mutation. J. Clin. Oncol. 2015, 33, 244-250. [CrossRef] [PubMed]

45. Maxwell, K.N.; Wubbenhorst, B.; Wenz, B.M.; De Sloover, D.; Pluta, J.; Emery, L.; Barrett, A.; Kraya, A.A.; Anastopoulos, I.N.; Yu, S.; et al. BRCA locus-specific loss of heterozygosity in germline BRCA1 and BRCA2 carriers. Nat. Commun. 2017, 8, 319. [CrossRef]

46. Coleman, R.L.; Oza, A.M.; Lorusso, D.; Aghajanian, C.; Oaknin, A.; Dean, A.; Colombo, N.; Weberpals, J.I.; Clamp, A.; Scambia, G.; et al. Rucaparib maintenance treatment for recurrent ovarian carcinoma after response to platinum therapy (ARIEL3): A randomised, double-blind, placebo-controlled, phase 3 trial. Lancet 2017, 390, 1949-1961. [CrossRef]

47. Farmer, H.; McCabe, N.; Lord, C.J.; Tutt, A.N.; Johnson, D.A.; Richardson, T.B.; Santarosa, M.; Dillon, K.J.; Hickson, I.; Knights, C.; et al. Targeting the DNA repair defect in BRCA mutant cells as a therapeutic strategy. Nature 2005, 434, 917-921. [CrossRef]

48. Drew, Y. The development of PARP inhibitors in ovarian cancer: From bench to bedside. Br. J. Cancer 2015, 113 (Suppl. 1), S3-S9. [CrossRef]

49. Husain, A.; He, G.; Venkatraman, E.S.; Spriggs, D.R. BRCA1 up-regulation is associated with repair-mediated resistance to cis-diamminedichloroplatinum(II). Cancer Res. 1998, 58, 1120-1123.

50. Sakai, W.; Swisher, E.M.; Jacquemont, C.; Chandramohan, K.V.; Couch, F.J.; Langdon, S.P.; Wurz, K.; Higgins, J.; Villegas, E.; Taniguchi, T. Functional restoration of BRCA2 protein by secondary BRCA2 mutations in BRCA2-mutated ovarian carcinoma. Cancer Res. 2009, 69, 6381-6386. [CrossRef]

51. Sawyer, S.L.; Tian, L.; Kahkonen, M.; Schwartzentruber, J.; Kircher, M.; Majewski, J.; Dyment, D.A.; Innes, A.M.; Boycott, K.M.; Moreau, L.A.; et al. Biallelic mutations in BRCA1 cause a new Fanconi anemia subtype. Cancer Discov. 2015, 5, 135-142. [CrossRef] [PubMed]

52. Weren, R.D.; Mensenkamp, A.R.; Simons, M.; Eijkelenboom, A.; Sie, A.S.; Ouchene, H.; van Asseldonk, M.; Gomez-Garcia, E.B.; Blok, M.J.; de Hullu, J.A.; et al. Novel BRCA1 and BRCA2 Tumor Test as Basis for Treatment Decisions and Referral for Genetic Counselling of Patients with Ovarian Carcinomas. Hum. Mutat. 2017, 38, 226-235. [CrossRef] [PubMed]

53. Heeke, A.L.; Pishvaian, M.J.; Lynce, F.; Xiu, J.; Brody, J.R.; Chen, W.J.; Baker, T.M.; Marshall, J.L.; Isaacs, C. Prevalence of Homologous Recombination-Related Gene Mutations Across Multiple Cancer Types. JCO Precis. Oncol. 2018, 2, PO.17.00286. [CrossRef] [PubMed]

54. Hughes-Davies, L.; Huntsman, D.; Ruas, M.; Fuks, F.; Bye, J.; Chin, S.F.; Milner, J.; Brown, L.A.; Hsu, F.; Gilks, B.; et al. EMSY links the BRCA2 pathway to sporadic breast and ovarian cancer. Cell 2003, 115, 523-535. [CrossRef]

55. Hollis, R.L.; Churchman, M.; Michie, C.O.; Rye, T.; Knight, L.; McCavigan, A.; Perren, T.; Williams, A.R.W.; McCluggage, W.G.; Kaplan, R.S.; et al. High EMSY expression defines a BRCA-like subgroup of high-grade serous ovarian carcinoma with prolonged survival and hypersensitivity to platinum. Cancer 2019, 125, 2772-2781. [CrossRef]

56. Liu, J.F.; Barry, W.T.; Birrer, M.; Lee, J.M.; Buckanovich, R.J.; Fleming, G.F.; Rimel, B.; Buss, M.K.; Nattam, S.; Hurteau, J.; et al. Combination cediranib and olaparib versus olaparib alone for women with recurrent platinum-sensitive ovarian cancer: A randomised phase 2 study. Lancet Oncol. 2014, 15, 1207-1214. [CrossRef] 
57. Matsumoto, K.; Nishimura, M.; Onoe, T.; Sakai, H.; Urakawa, Y.; Onda, T.; Yaegashi, N. PARP inhibitors for BRCA wild typse ovarian cancer; gene alterations, homologous recombination deficiency and combination therapy. Jpn J. Clin. Oncol. 2019, 49, 703-707. [CrossRef]

58. Richards, S.; Aziz, N.; Bale, S.; Bick, D.; Das, S.; Gastier-Foster, J.; Grody, W.W.; Hegde, M.; Lyon, E.; Spector, E.; et al. Standards and guidelines for the interpretation of sequence variants: A joint consensus recommendation of the American College of Medical Genetics and Genomics and the Association for Molecular Pathology. Genet. Med. 2015, 17, 405-424. [CrossRef]

Publisher's Note: MDPI stays neutral with regard to jurisdictional claims in published maps and institutional affiliations.

(C) 2020 by the authors. Licensee MDPI, Basel, Switzerland. This article is an open access article distributed under the terms and conditions of the Creative Commons Attribution (CC BY) license (http://creativecommons.org/licenses/by/4.0/). 